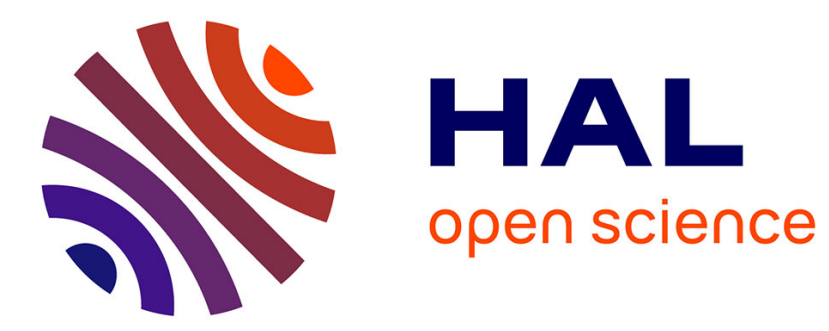

\title{
Toward Human-Centric Factories: Requirements and Design Aspects of a Worker-Centric Job Allocator
}

Gokan May, Omid Maghazei, Marco Taisch, Andrea Bettoni, Marco Cinus, Annarita Matarazzo

\section{- To cite this version:}

Gokan May, Omid Maghazei, Marco Taisch, Andrea Bettoni, Marco Cinus, et al.. Toward HumanCentric Factories: Requirements and Design Aspects of a Worker-Centric Job Allocator. IFIP International Conference on Advances in Production Management Systems (APMS), Sep 2014, Ajaccio, France. pp.417-424, 10.1007/978-3-662-44733-8_52 . hal-01387282

\section{HAL Id: hal-01387282 \\ https://hal.inria.fr/hal-01387282}

Submitted on 25 Oct 2016

HAL is a multi-disciplinary open access archive for the deposit and dissemination of scientific research documents, whether they are published or not. The documents may come from teaching and research institutions in France or abroad, or from public or private research centers.
L'archive ouverte pluridisciplinaire HAL, est destinée au dépôt et à la diffusion de documents scientifiques de niveau recherche, publiés ou non, émanant des établissements d'enseignement et de recherche français ou étrangers, des laboratoires publics ou privés.

\section{(c)(1)}

Distributed under a Creative Commons Attribution| 4.0 International License 


\title{
Toward Human-centric Factories: Requirements and design aspects of a worker-centric job allocator
}

\author{
Gökan May ${ }^{1}$, Omid Maghazei ${ }^{1}$, Marco Taisch $^{1}$, Andrea Bettoni $^{2}$, \\ Marco Cinus $^{2}$, and Annarita Matarazzo ${ }^{1}$ \\ ${ }^{1}$ Politecnico di Milano, Department of Management, Economics and Industrial Engineering, \\ Piazza Leonardo da Vinci 32, Milano, 20133, Italy \\ \{gokan.may, omid.maghazei, marco.taisch\}apolimi.it \\ ${ }^{2}$ University of Applied Sciences and Arts of Southern Switzerland, ISTePS, Galleria \\ 2 Via Cantonale 2c, CH-6928 Manno, Switzerland \\ \{andrea.bettoni, marco.cinus\}@supsi.ch
}

\begin{abstract}
The new point of view in which factory and workers are seen is the person at the centre of the production system, so employees should be involved in job design and task balancing processes. The advantages coming by this paradigm shift, from the task-centric organization to the worker-centric factory is doubtless the high correlation among job and worker in terms of skill, experience, and worker's features. Human-centric system is useful to improve the knowledge and the capabilities of workers regardless of age and role, and in this kind of model the job suits the worker and his needs. In this context, it is of paramount importance to design and develop a worker-centric job allocator tool in which the human dimension is a key factor. This study therefore addresses the requirements and design aspects of a worker-centric job allocator as an enabler for human-centric workplaces of the future.
\end{abstract}

Keywords: worker-centric job allocator, human-centric factory, sustainable manufacturing, social sustainability, factories of the future

\section{$1 \quad$ Introduction}

The manufacturing sector needs to react and adapt to the emerging sustainability trend, not only for environmental and economic reasons but also for social ones. In this sense, the new point of view in which factory and workers are seen is the person at the centre of the production system, so employees should be involved in job design and task balancing processes. The advantages coming by this paradigm shift, from the task-centric organization to the worker-centric factory is doubtless the high correlation among job and worker in terms of skill, experience, and worker's features. The new human-centric factory model in the Figure 1 below, as developed by the authors in May et al. (2014), highlights the needs and important aspects for designing the human-centric workplaces of the future whilst addressing the problem from different perspectives (i.e. worker, factory, and context). 


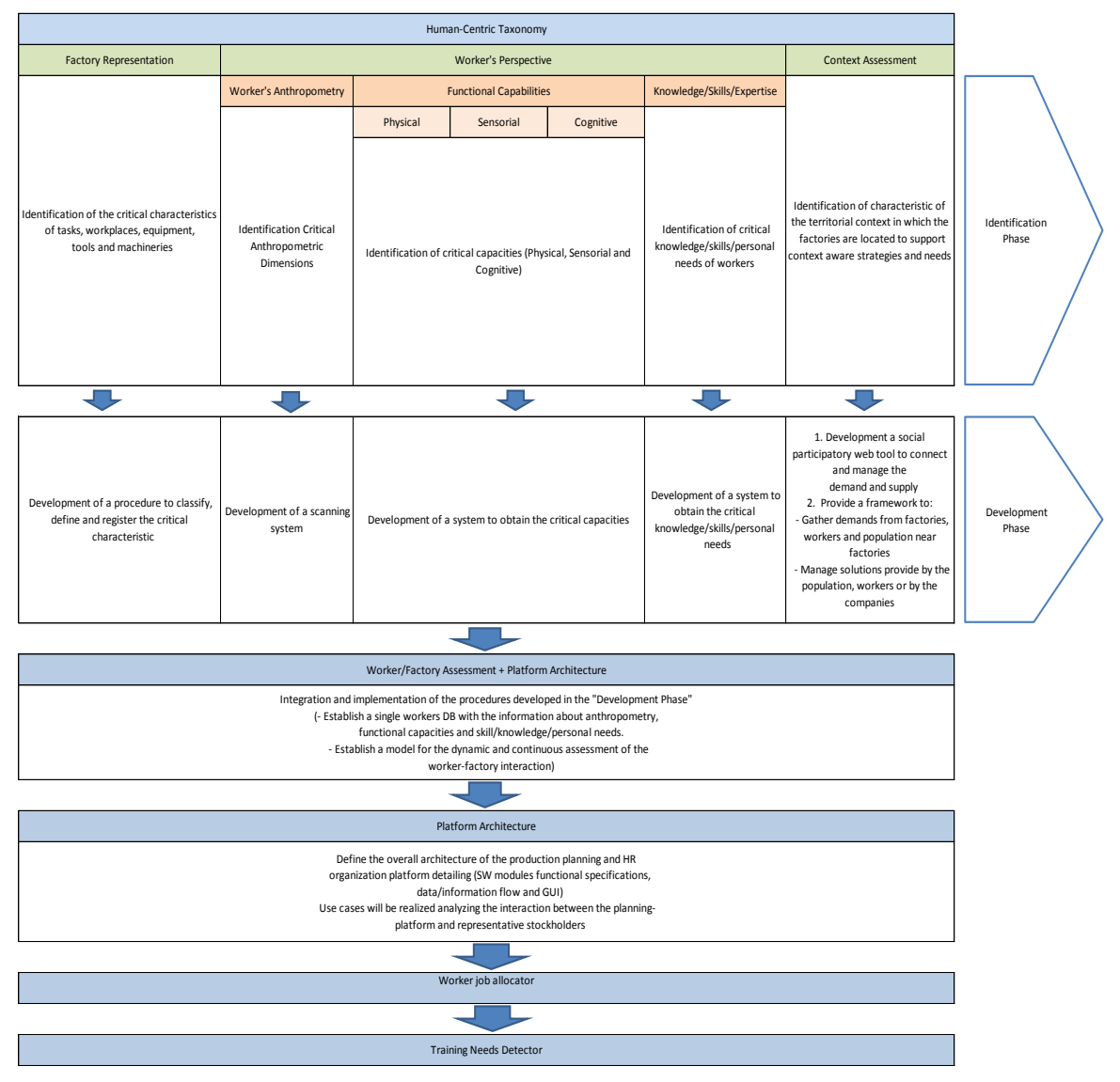

Fig. 1. A new Human-centric Factory Model [1] (May et al., 2014)

Human-centric system is useful to improve the knowledge and the capabilities of workers regardless of age and role, and in this kind of model the job suits the worker and his needs. In this context, it is of paramount importance to design and develop a worker-centric job allocator tool in which the human dimension is a key factor. Thus, in this research we address the research question " "How can the jobs in a workplace be allocated to workers to create human-centric workplaces?", on the way to design a worker-centric job allocator in which worker's skills, capacities and needs are considered. This study therefore aims at analyzing requirements and design aspects of a worker-centric job allocator to be used in human-centric workplaces of the future.

\section{Theoretical Background}

The review work in this section aims at describing the state of the art for traditional job allocation algorithms, and to find the bridges and the gaps between them and the relatively new research fields of worker-centric job allocator. 
One of the main optimization problems in operations research is job allocation, and it aims at finding a maximum weight matching based on specific multi objective function or criteria. Thus, the problem of job allocation to tasks and workplaces is characterized by a large number of different possibilities for allocating employees to work functions [2]. There are many models for an optimal personnel assignment, but none of these incorporate the concept of human dimension in a holistic manner. The main aspect of a proper job allocator is the consideration of human factors like abilities, preferences, restrictions, and needs.

Dependent upon the type of personnel assignment problem, various instruments have been developed [3]. For instance, the ifab-Institute of Human and Industrial Engineering at the University of Karlsruhe develops a personnel-oriented simulation tool that considers the complex, dynamic interactions of personnel resources and machinery equipment and takes advantage of the vast array of opportunities for the planning and reassigning of personnel to work functions.

Zuelch, in his paper [3], highlights the key concepts in the way to design and conceive a worker-centric job allocator. However, the focus here is only on production planning, and themes like worker's abilities, preferences, skills, needs are only considered to the medium term production planning.

Corominas, in his research work [4] describes and models the allocation of a set of tasks to a set of workers, when the worker's performance on a task depends on the experience of the worker of this task and of the other tasks involved. The objective is to minimize the completion time. The model is very interesting because the performance is, at least in part, a consequence of experience. When a set of tasks is being performed, the experience acquired in the first stages can obviously influence the capacity of the worker to do this task and other tasks later. Despite this, the model takes into account only the experience factor and is not part of a worker-centric vision. There are essential elements missing in the model, such as needs, preferences, skills, features, and knowledge of workers.

Besides, Lin [5] constructs a general fuzzy assignment problem (GFAP) based on a real scenario and proposes a solution procedure. The model is based on a project team composed by $n$ workers and a manager. The $n$ workers are responsible for performing $\mathrm{n}$ jobs and the manager for restraining the total cost. Using the max-min criterion, a mixed nonlinear programming model of the GFAP is constructed, and an algorithm that combines simplex and trade-off approaches is proposed to solve the problem. In this model, the only objective is the increasing of team performance but main aspects of worker centric model are not considered. Thus, one weakness of the model could be the missing human dimension. However, the algorithm is very interesting and with some modifications could be used for future researches in designing worker-centric job allocators.

Koltai [6] suggests a balancing model for assembly workstations. The model assigns tasks to workstation taking into account skill requirement of tasks and skill level of workers (i.e. under skilled, average, and specialized). Nonetheless, this type of assignment is not dynamic because skills have been categorized a priori.

In traditional job allocation, algorithms are used in static way. However, it is important to have dynamic allocation of resources considering workers' evolution. 
The main gap found in the critical analysis of the literature is that models for job allocator and resource assignment are static. In the human-centric point of view, workers evolve during time, in which they could improve skills thanks to experience and training, change functional or anthropometric characteristics, improve knowledge, reconsider personal needs. So, the structure of job allocator should be dynamic, updating resource allocation based on workers' profile. Hence, this could enable us to redefine tasks, operations, jobs considering evolution of worker, factory, and contextual drivers. So, the worker-centric job allocator described in this work is built to address these emerging gaps.

\section{The Worker-centric Job Allocator}

Job allocator module is a customer-centric production planning tool meant to dynamically assign the available workers to the different tasks and jobs considering workers' relevant characteristics, skills and availabilities; short-term production plans; time-schedules; job and task description. Different alternative jobs-workers matching are then ranked utilizing the assessment module. Job allocator runs when the Production Manager needs to identify the better performing allocation of resources and to better manage human resources. This software module works on a short term basis and has a dedicated GUI for showing alternative for managing data entry, definition of allocation rules and for visualizing job allocations. Further considerations for this tool might be to have dedicated areas in which manager could find the best allocation by using filtering questions, and to have a customized and modular software tool in order to re-use the same software in different factory areas like technical department, production systems and other units.

\subsection{Needs}

The resource allocation in a company is a complex activity that employs many people in the organization. Big companies have a special department which deals this job. Despite all, for human resource management, it is difficult to take into account all worker's needs. The job allocator in a broad sense allows to assign tasks and jobs to the resources in a different way.

First of all, the analysis starts from a deep knowledge of the workers and their needs. This information becomes evaluation parameters to build the worker history and through these data, it is possible to better know the worker and to forecast the future needs, for example trainings. The tasks are then allocated according to the "best available resource" to perform that given asset. In this perspective, the role of training results are needed to improve knowledge and capabilities of each worker.

To derive the basic needs and requirements for a worker-centric job allocator, the process started with the interviews with two case companies from white goods and tooling industries. The companies listed the following functions as important for job allocator to be designed: communicate with work profiler; take into account a defined population; choose the best match between workstation skill requirements and worker profile to minimize the training gap up-front; choose best match for each workstation on a set of workstations, in order to avoid looping; minimize the computational time; 
management of skill matrix - according to the critical workstation; identify the person who is the closest match to be trained in addition to that workstation, minimizing the training gap, matching interests and physical worker profile; have dedicated areas in which manager could find the best allocation by using filtering questions; a customized and modular software tool in order to re-use the same software in different factory areas like technical department, production systems and other units.

Besides, outputs required from job allocator tools are listed as for each workstation a list of operators with skills and qualifications, physical characteristics and limitations; and indication of match against workstation requirements and hints for designing workstations.

Despite the fact that defining an objective function is left as a further research stream, it is possible to define it in a generic way. According to the companies interview, it is better to shape a multi-objective function.

A multi-objective problem is defined as $\max \left\{\mathrm{f}_{1}(\mathrm{x}), \mathrm{f}_{2}(\mathrm{x}), \ldots, \mathrm{f}_{\mathrm{k}}(\mathrm{x})\right\}$ where $\mathrm{Rk}$ is the objective space. The multi-objective function for job allocator takes into account different objectives, some of them can be: maximize productivity $\mathrm{P}$; maximize worker's satisfaction $\mathrm{S}$; and minimize workers' related costs $\mathrm{C}$.

Also, each single objective could be further specified into a set of decision variables along with a set of parameters. In this case decision variables can be workstations $\mathrm{Wi}=1,2, . ., \mathrm{N}$ in a production system. Furthermore, constraints could be defined in a generic way accordingly, for example:

$c_{1}$ : Assembly time for each workstation doesn't exceed the total working time T

$\mathrm{c}_{2}$ : Anthropometric factor $\mathrm{AFi}$ for each workstation is at least higher than the minimum required $\mathrm{AF}_{\text {min }}$

The objective function might be defined as $\max \{\mathrm{P}, \mathrm{S},-\mathrm{C}\}$, where $\mathrm{c} 1 \leq \mathrm{T}$, $\mathrm{c} 2 \geq \mathrm{AF}_{\min }$, and $\mathrm{W}_{\mathrm{i}} \geq 0$

\subsection{Requirements}

Requirements analysis in systems engineering and software engineering, encompasses those tasks that go into determining the needs or conditions to meet for a new or altered product, taking account of the possibly conflicting requirements of the various stakeholders, analyzing, documenting, validating and managing software or system requirements [7].

It is possible to identify several types of requirements. In the following subsections will be listed three types of system requirements: functional, non-functional and technological. Requirements listed are MUST requirements, this means that the implementation of those requirements is essential to meet the initial specification to which the project is designed.

Functional Requirements. Functional requirements explain what has to be done by identifying the necessary task, action or activity that must be accomplished [8]. Functional requirements represent what user can do. Based on this, user can: create, delete, update worker data and its profile; share info with other company location/offices/premises; consult the system in every moment; find automatically the best job allocation; update the objective functions for the resource allocation; evaluate the different options on the basis of the objective functions; put in the system data of 
worker-factory-context; compare graphically different alternatives; and visualize statistics in different ways.

Non-Functional Requirements. Non-functional requirements are requirements that specify criteria that can be used to judge the operation of a system, rather than specific behaviours. Non-functional requirements represent what system does. So, system: shows the workers list; shows measured data from each worker; shows the jobs' list; shows skills required from each job; compares worker skills with skills required for a specific job; communicates with existing production plan's data source (ERP); provides the optimum resource allocation considering worker-centricity; provides statistics; provides different alternatives for resource allocation; evaluates different options for resource allocation; keeps track of all job-worker alternatives; allows the communication among Job Allocator and job assessment modules; stores and retrieves data from knowledge database; allows the communication among Job Allocator and data coming from production plans; and provides a graphic interface in order to compare job-worker alternatives.

Technological Requirements. As technical requirement, system should have a GUI, a database, and different modules.

\subsection{Use Case Diagram and Scenario}

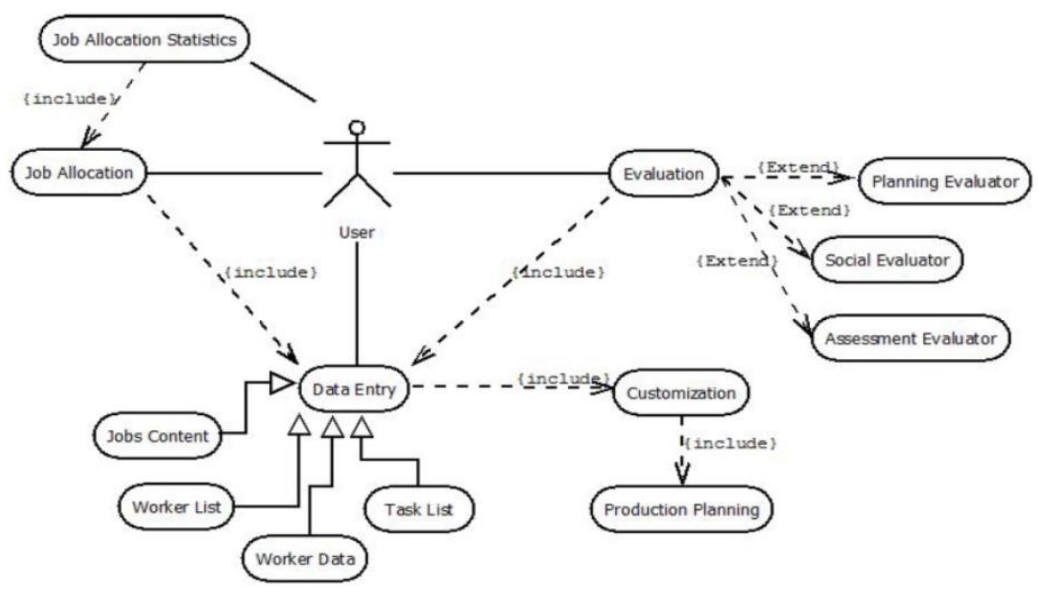

Fig. 2. Use Case Diagram

A use case diagram is a representation of a user's interaction with the system and depicting the specifications of a use case. As highlighted in the above use case diagram, the scenario is explained below:

- User can visualize suggested allocations, that is a list of jobs with assigned workers to each of it;

- User can evaluate job allocation alternatives;

- User can visualize job allocation statistics, that are statistics of jobs-workers matching;

- User can enter the required relevant data; 
- To visualize statistics, it is necessary to have job allocation lists (include);

- Job Allocation and Evaluation have 'Data Entry' as a common feature (include);

- Evaluation is possible through different evaluator tools: planning evaluator, social evaluator, assessment evaluator (extend);

- Data Entry actions can be Job Content, Worker List, Worker Data and Task List;

- Customization is possible only through Data Entry (include): this function allows to customize the objective function.

- Production Planning is an external data source which stores production plans. The access to this tool is possible by Customization (include).

\subsection{Class Diagram and Software Architecture}

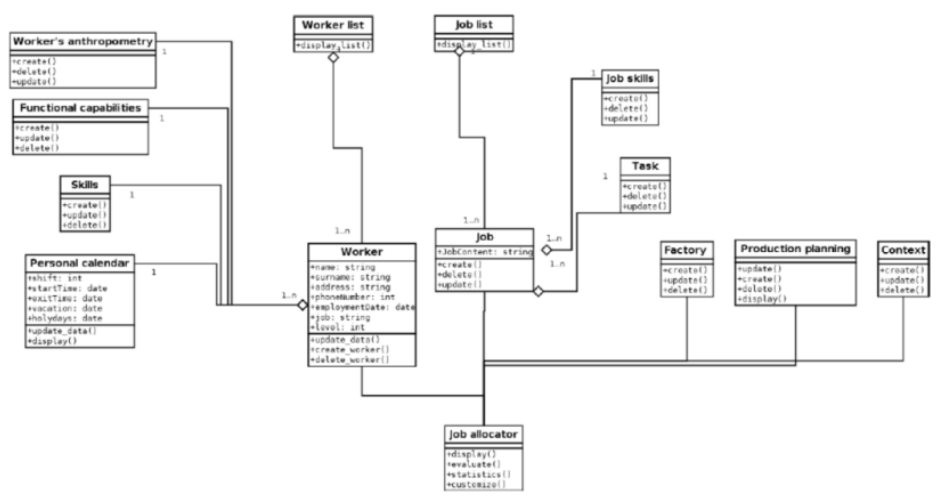

Fig. 3. Class Diagram for the worker-centric job allocator

During the design phase of a software, it is very important to define the static view of the system, and a class diagram defines the basic elements in this context. The Figure 3 above hence illustrates the class diagram for the worker-centric job allocator.

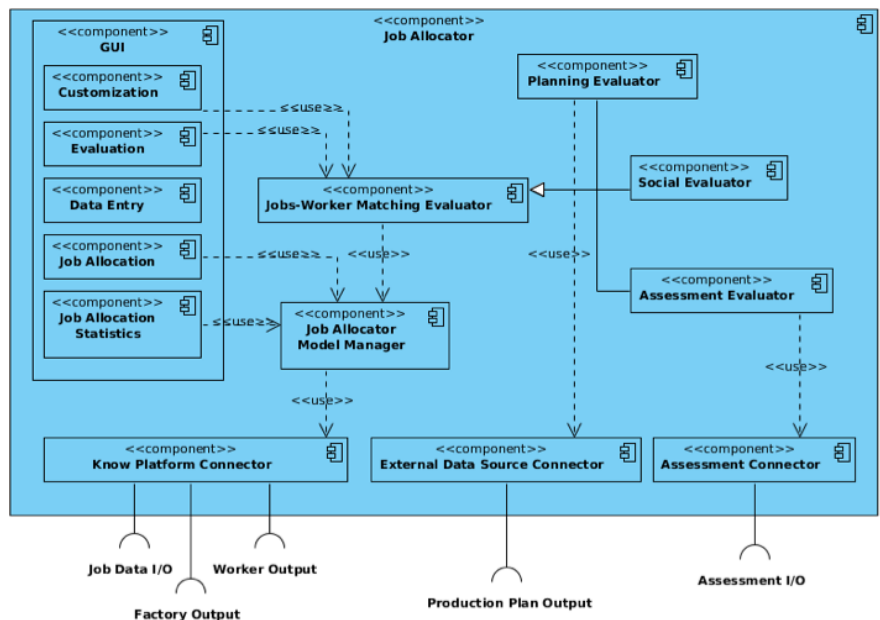

Fig. 4. Job allocator component diagram 
The Figure 4 above represents the architecture of the job allocator software module which include the software elements and relationships in between them. Thus, building and documenting the software architecture fosters communication between stakeholders, and speeds up the decision process for the high-level design [9].

\section{Conclusion}

Designing human-centric workplaces of the future gains more and more importance in achieving socially sustainable factories and hence workers' satisfaction, which could lead to improvement of the overall performance in manufacturing plants. One of the main pillars in this direction is to design and assign jobs which better fit to workers' skills, characteristics, and needs. In this study, we analyzed the industrial needs and the requirements for designing such worker-centric job allocator. Hence, the results achieved and insights gained based on this study open the way toward development of software modules for worker-centric job allocation for building human-centric factories of the future. Further research could focus on the development of training needs detector tool in the same way adopted for the job allocator tool.

\section{Acknowledgement}

This work has been partly funded by the European Commission through Man-Made project (Grant Agreement No: FoF.NMP.2013-3 6090730). The authors wish to acknowledge the Commission for its support. The authors also wish to acknowledge their gratitude and appreciation to all the Man-Made partners for their contribution during the development of various ideas and concepts presented in this work.

\section{References}

1. May, G., Taisch, M., Bettoni, A., Maghazei, O., Matarazzo, A., Stahl, B.: A new Humancentric Factory Model. 12 ${ }^{\text {th }}$ Global Conference on Sustainable Manufacturing. Procedia CIRP (2014). (Forthcoming)

2. Burkard R., Dell'Amico M., Martello S.: Assignment Problems. ISBN 978-1-61197-2221. SIAM (2012).

3. Zuelch G., Rottinger S., Vollstedt T.: A simulation approach for planning and re-assigning of personnel in manufacturing. Int. J. Production Economics 90, 265-277 (2004).

4. Corominas A., Olivella J., Pastor R.: A model for the assignment of a set of tasks when work performance depends on experience of all tasks involved. Int. J. Production Economics 126, 335-340 (2010).

5. Lin C.-J.: Assignment problem for team performance promotion under fuzzy environment. Mathematical Problems in Engineering 6 (2013).

6. Koltai T.: Formulation of Multi-Level Workforce Skill Constraints in Assembly Line Balancing Models, Manufacturing Modelling, Management, and Control 7(1), 772-777 (2013).

7. Hay, D. C.: Requirements Analysis: From Business Views to Architecture (1st ed.), Upper Saddle River, NJ: Prentice Hall, ISBN 0-13-028228-6 (2003).

8. Laplante, P.: Requirements Engineering for Software and Systems (1st ed.), Redmond,WA: CRC Press. ISBN 1-4200-6467-3 (2009).

9. Bass, L., Clements P., Kazman R.: Software Architecture In Practice, Third Edition, Addison-Wesley. pp. 21-24. ISBN 978-0321815736 (2012). 